\title{
The Dependence of Electrochemical Behaviors on the Corrosion Products of L360NCS Steel Exposed to Wet H2S Environments
}

\author{
Liqiang Chen, Jie Zhou, Yuxin Chen, Pengpeng Bai, Jian Wu, Shuqi Zheng* \\ Beijing Key Laboratory of Failure, Corrosion and Protection of Oil/gas Facilities and Department of \\ Materials Science and Engineering, China University of Petroleum, Beijing 102249, P R China \\ *E-mail: zhengsq09@163.com
}

doi: $10.20964 / 110355$

Received: 10 January 2016 / Accepted: 29 February 2016 / Published: 1 April 2016

\begin{abstract}
The corrosion behavior and electrochemical characteristics of carbon steel in $\mathrm{H}_{2} \mathrm{~S}$ environment were investigated in this paper under different temperatures. Results showed that the corrosion rate of steel increased first from $0.413 \mathrm{~mm} / \mathrm{a}$ to $0.889 \mathrm{~mm} / \mathrm{a}$ with the temperature changed from 25 to $75{ }^{\circ} \mathrm{C}$, and then decreased to $0.298 \mathrm{~mm} / \mathrm{a}$ with the temperature increased to $90{ }^{\circ} \mathrm{C}$. Electrochemical impedance spectroscopy (EIS) showed that the reaction presented charge-transfer and diffusion-controlled mechanism when temperature ranged from 25 to $75{ }^{\circ} \mathrm{C}$; while at $90{ }^{\circ} \mathrm{C}$, the result showed a chargetransfer reaction. The polarization curve revealed the linear polarization resistance (LPR) decreased first and then increased as temperature rose. The results related to the reduced solubility of $\mathrm{H}_{2} \mathrm{~S}$ in water and enhanced reaction rate with increased temperature. Mackinawite was the main corrosion product, and the ratio of mackinawite increased while the grain size of corrosion products decreased with the increase of temperature.
\end{abstract}

Keywords: Carbon steel; Electrochemical impedance spectroscopy (EIS); Oil and gas; Sulfidation; Weight loss

\section{FULL TEXT}

(C) 2016 The Authors. Published by ESG (www.electrochemsci.org). This article is an open access article distributed under the terms and conditions of the Creative Commons Attribution license (http://creativecommons.org/licenses/by/4.0/). 